\title{
The Postnatal Subventricular Zone: A Source of New Cells in This Old Brain
}

\author{
Angélique Bordey, PhD \\ Departments of Neurosurgery, \\ and Cellular \& Molecular Physiology \\ Yale University School of Medicine \\ New Haven, Conneticut \\ USA
}

\author{
Address for correspondence: \\ Angélique Bordey, PhD \\ Department of Neurosurgery \\ Yale University School of Medicine \\ 333 Cedar Street, FMB 422 \\ New Haven, Conneticut 06520-8082 \\ USA \\ Email: angelique.bordey@yale.edu
}

Received, December 19, 2004

Accepted, December 26, 2004
Findings over the past decades demonstrating persistent neurogenesis in the adult brain have challenged the view of a fixed circuitry and raise hopes for self-renewal following brain injury. The subventricular zone (SVZ, also called subependymal layer, SEL) lining the lateral wall of the lateral ventricle is the largest germinal center where stem cells displaying astrocytic traits have been identified. These astrocyte-like cells ensheath neuroblasts, which migrate throughout the SVZ and along the rostral migratory stream to the olfactory bulb where they differentiate into interneurons. The cellular architecture of the SVZ has been essential for the development of hypotheses to explain how intercellular signaling and non-synaptic communication could regulate neurogenesis. An array of signaling molecules have recently been identified that may offer future strategies to promote neurogenesis and reroute neuroblasts to higher cognitive centers.

Key Words: brain, neurogenesis, subventricular zone
$\mathrm{T}$ he existence of cells with stem cell attributes in two regions of the adult central nervous system (CNS) has overturned the long-held dogma that neurons are formed exclusively before birth and has raised hopes that self-renewal leading to repair may be possible in the mature CNS. These two regions include the SVZ also called SEL ${ }^{24}$ and the subgranular zone of the hippocampal dentate gyrus. This review focuses on the SVZ, which contains the largest pool of dividing neural precursors in the adult brain. ${ }^{4,26}$ Early in the past century Allen in 1912 identified mitotic cells in the SVZ of the lateral wall of the lateral ventricle in adult rats. ${ }^{1}$ Later in the $1960 \mathrm{~s}$, Altman proposed that immature SVZ cells migrate to the olfactory bulb where they differentiate into mature neurons and glia. ${ }^{4}$ However, according to Smart (1960), cell migration was thought to be minimal in adults. ${ }^{105}$ It is only in the 1990s that focal labeling of the SVZ in the neonate, ${ }^{69}$ and adult ${ }^{37,66}$ indicated that proliferating SVZ cells migrate through the SVZ and along the rostral migratory stream (RMS, also called SVZ rostral extension ${ }^{91}$ ) into the olfactory bulb where they differentiate into interneurons. At almost the same time, the presence of cells with stem cell attributes (i.e. self-renewal and multipotency) in the SVZ was identified. ${ }^{80,97}$ These findings opened a new field of investigation that triggered a rapidly increasing number of studies performed by research groups throughout the world. The present review gives a brief synopsis (mostly from studies in rodents) on the architecture of the SVZ, the identity of the stem cells in the SVZ, ${ }^{7,36}$, the signaling molecules modulating neurogenesis, ${ }^{35,104}$ and finally the potential strategies to promote neurogenesis. ${ }^{49,92}$ The present review is focused on the postnatal and adult SVZ but not on the neonatal SVZ where neurogenesis and extensive gliogenesis coexist. ${ }^{62,63,73}$

\section{In Search of the Neural Stem Cells}

First, here is a brief description of the lineage and nomenclature. Stem cells are defined as undifferentiated cells capable of proliferation, self-renewal and multipotency (i.e. they can give rise to multiple differentiated cell types). Figure 1 defines the different terms used to describe immature cells that are called precursors or progenitors.

\section{Description of the Cellular Architecture of the SVZ}

The architecture of the SVZ has been the subject of several reviews, ${ }^{45,91}$ and will be briefly summarized here. It is important to point out that most studies referred to the midSVZ or striatal SVZ along the lateral ventricle but not the SVZ in the dorso-lateral portion or the ventral part of the ventricle (Figure 2A \&B). It is likely that the dorsolateral and ventral parts of the SVZ display a different cellular architecture and cells with different properties than those in the mid-SVZ. For example, cells with a radial glial morphology remain in the ventral part of the SVZ while they disappear from other SVZ parts. ${ }^{110}$ At the light microscopic level, the SVZ appears as a rather homogeneous tissue, formed by small, tightly packed cells, easily distinguishable from the adjacent ependyma and mature nervous tissue (Figure 2C). ${ }^{2,58,95,105}$

Earlier studies based on Nissl staining or other histological methods described the presence of two major cell types that were collectively called subependymal cells. ${ }^{2,17,105}$ Early electron microscopic studies ${ }^{17}$ showed that numerous subependymal cells displayed the features of highly undifferentiated cells while the remaining cells were considered predominantly as astrocytes with a few as 


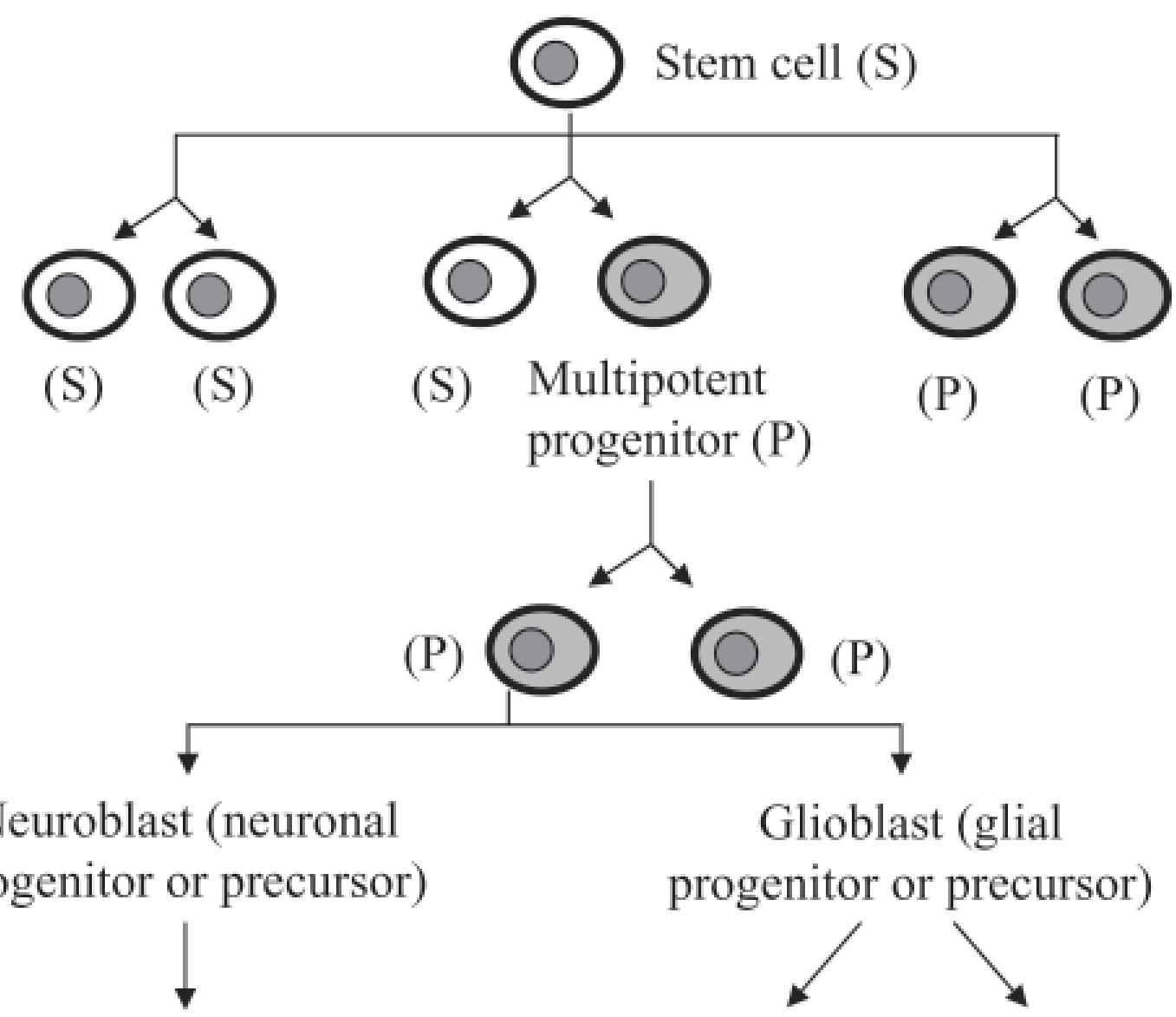

Neurons

Oligodendrocyte Astrocyte

Figure 1. Definition and nomenclature of neural stem cell progeny. Neural stem cells are indefinitely self-renewing cells that can generate any cell type in the CNS. Stem cells (S) can divide and give rise to two identical daughter cells, or to one cell identical to itself and a more developmentally differentiated multipotent progenitor (P), or to two multipotent progenitors. These progenitors are capable of limited self-renewal before differentiating into lineage-committed offsprings termed neuroblasts and glioblasts (or neuronal and glial progenitors, respectively). These two cell populations can still replicate and generate progeny that remain within the committed lineage. The lineage-restricted progenitors then differentiate to give rise to mature neurons and glial cells.

microglia. More recent studies ${ }^{54,67,90}$ confirmed that the SVZ of adult rodents contains two main cell types. The first cell type, referred to as type $\mathrm{A}^{54}$ or class $1^{54}$ or subependymal cell, ${ }^{90}$ is very electron dense and shows the ultrastructural features of undifferentiated, migrating neuroblasts. These cells have an elongated, bipolar shape with one or two main processes emerging from the opposite poles. The second cell type, referred to as type $\mathrm{B}^{67}$ or class $2,{ }^{54}$ is a particular type of protoplasmic astrocyte, which is less abundant than the undifferentiated cells (about a 1:4 ratio).

A recent ultrastructural analysis confirmed that undifferentiated precursors and the so-called astrocytes (type B cell) are the two main cell types lying between the ependymal cells and the striatal parenchyma in the adult
SVZ. ${ }^{39}$ The type B cells will be referred to as astrocyte-like cells here because they share some but not all of the properties of astrocytes (vide infra). This study further suggested that type A cells were the neuroblasts migrating to the olfactory bulb. However, it is worth mentioning that the authors identified a third cell type, called type C cells, which are scattered throughout the SVZ and incorporate tritiated thymidine, suggesting that they might correspond to constitutively proliferating precursors or presumably bipotential progenitors. Second, the same authors distinguished two types of astrocyte-like cells, indicated as type B1 and type B2 (smaller and more electron dense than type B1) that were adjacent to ependymal cells and located at the interface with the striatal parenchyma, respectively. 

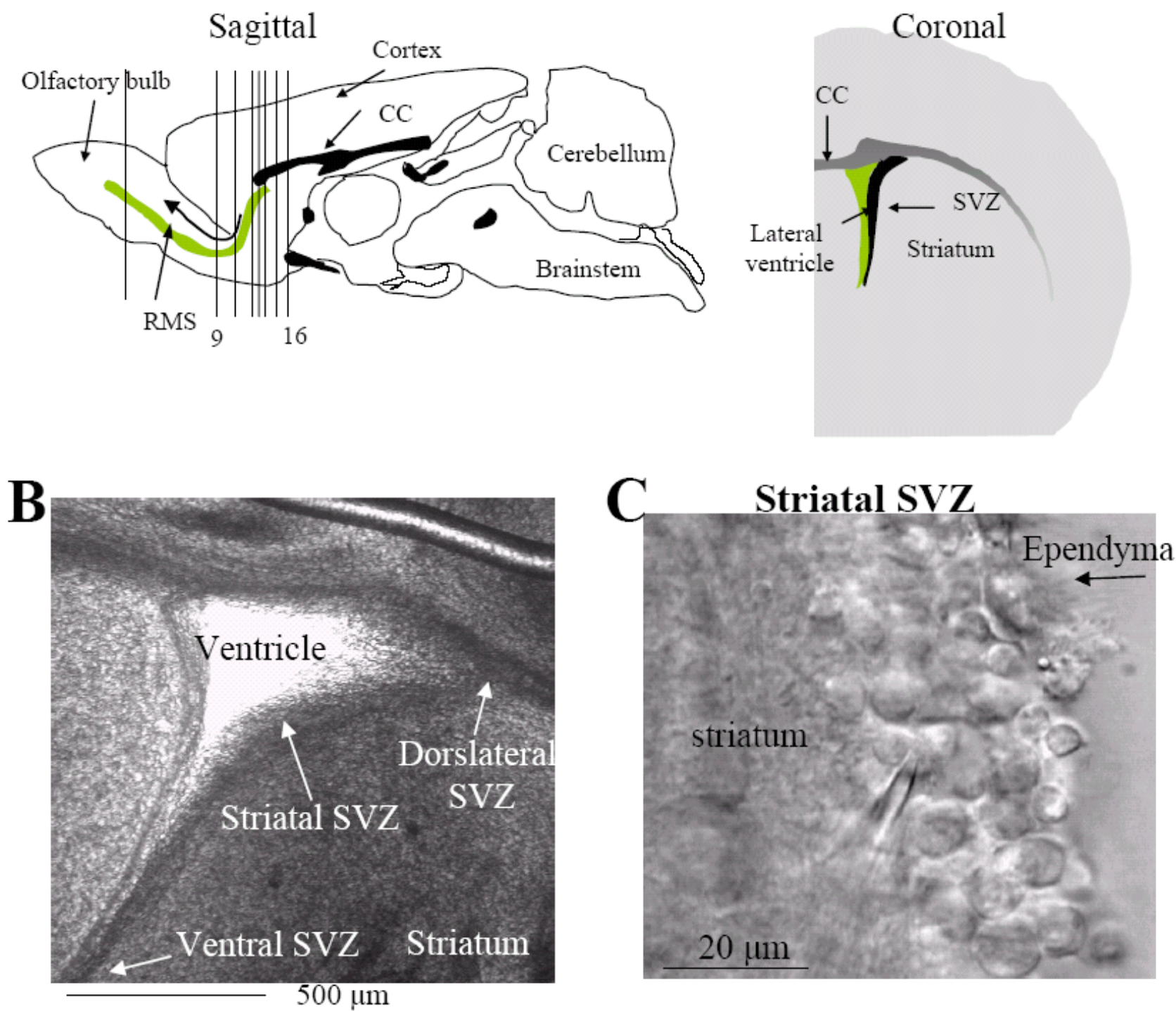

Figure 2. Location and architecture of the SVZ. A) Schematic view of a sagittal (left) and a coronal (right) section of the adult mouse brain. The lateral ventricle is located under the corpus callosum (CC). The rostral migratory stream (RMS) is highlighted in green in the sagittal section. B) Photographs (4x magnification) of a coronal section of the SVZ taken using infrared DIC optics. The SVZ lines the lateral side of the lateral ventricle and extends between the CC and striatum. The ventral, striatal and dorso-lateral parts of the SVZ are indicated on the photograph. C) High magnification photograph of precursors in the striatal SVZ.

Some type B2 cells were also observed to incorporate tritiated thymidine. Finally, the proportion of type A (neuroblast), B (astrocyte-like cells) and C (bipotential progenitors) cells differ along the rostro-caudal axis of the brain.

Cells in the SVZ and in the RMS display a specific arrangement defining two cellular compartments. Neuroblasts can be selectively detected by antibodies raised against the poly-sialylated form of the neural cell adhesion molecule (PSA-NCAM), ${ }^{20,39,100}$ class III á-tubulin $(\mathrm{TuJ} 1)^{39}$ and doublecortin, ${ }^{116}$ while astrocyte-like cells can be marked with antibodies against glial fibrillary acidic protein $(\text { GFAP })^{39}$ and the astrocytic glutamate transporter GLAST (Figure 3A). ${ }^{19,25}$ These antibodies revealed that the migrating cells form longitudinal chains (in sagittal sections) or clusters (in coronal sections) ensheathed by the processes of astrocyte-like cells (Figure 3B) that separate the migrating cells from the mature tissue..$^{19,67,90}$ While the chains are highly organized in the RMS, they appear looser in the SVZ where they form a three-dimensional network ${ }^{37}$

Summary of organization: The SVZ-ependymal region contains at least four different cell types defined by their morphology, ultrastructure, and molecular markers. The migrating neuroblasts (type A cells) form chains ensheathed by astrocyte-like cells (type B cells). More spherical and highly proliferative precursors (type $\mathrm{C}$ cells) form clusters next to the chains of migrating neuroblasts. The SVZ is largely separated from the ventricle cavity by a layer of ependymal cells (previously called typeE cells). Astrocytelike cells interact closely with ependymal cells and occasionally contact the ventricle lumen. 


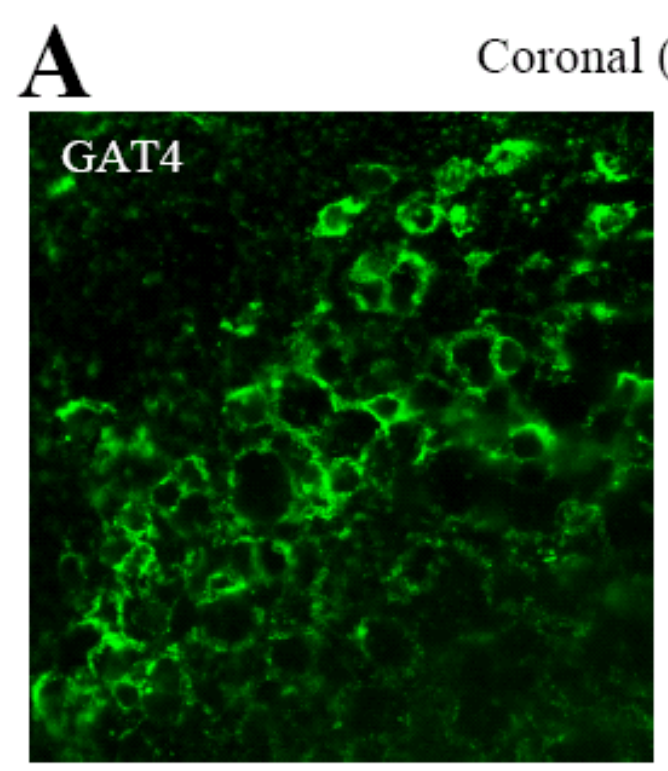

(RMS)
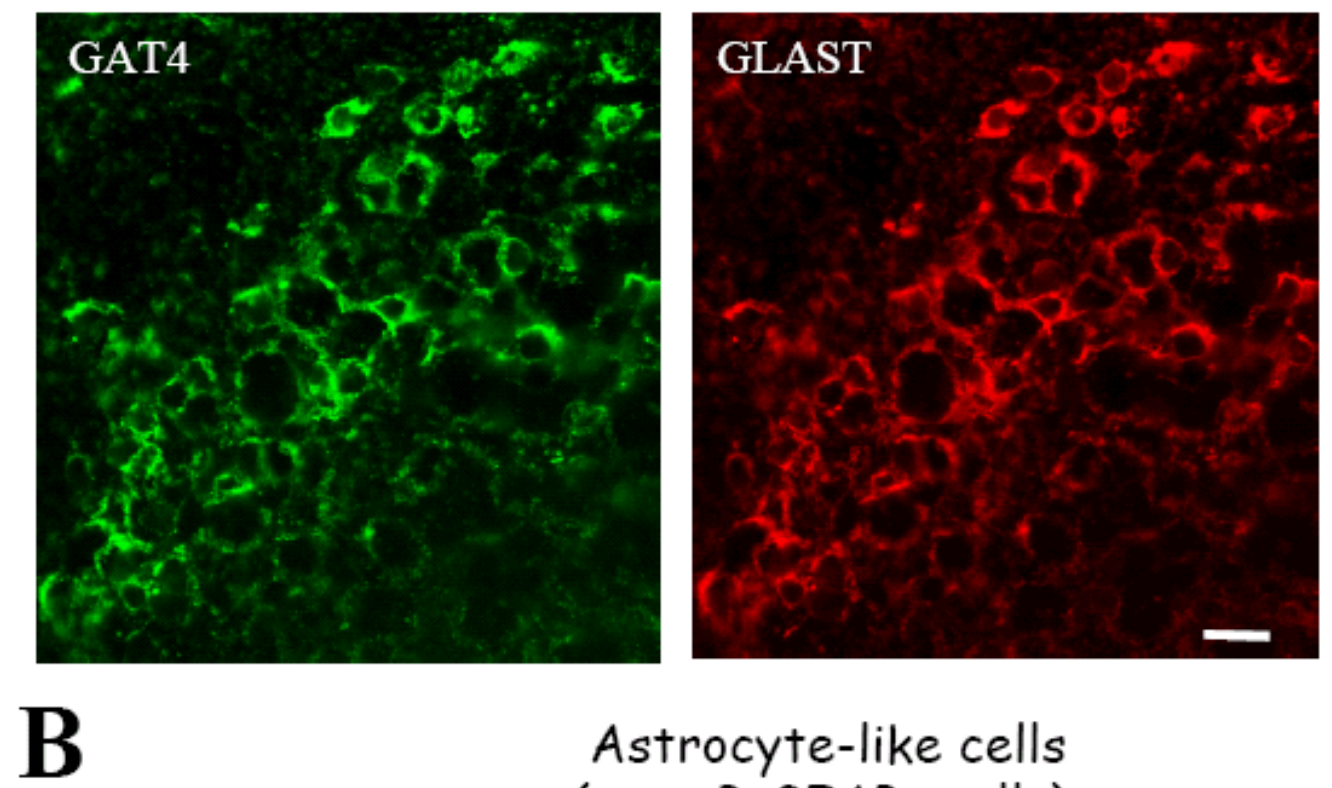

B

Astrocyte-like cells

(type B-GFAP+ cells)

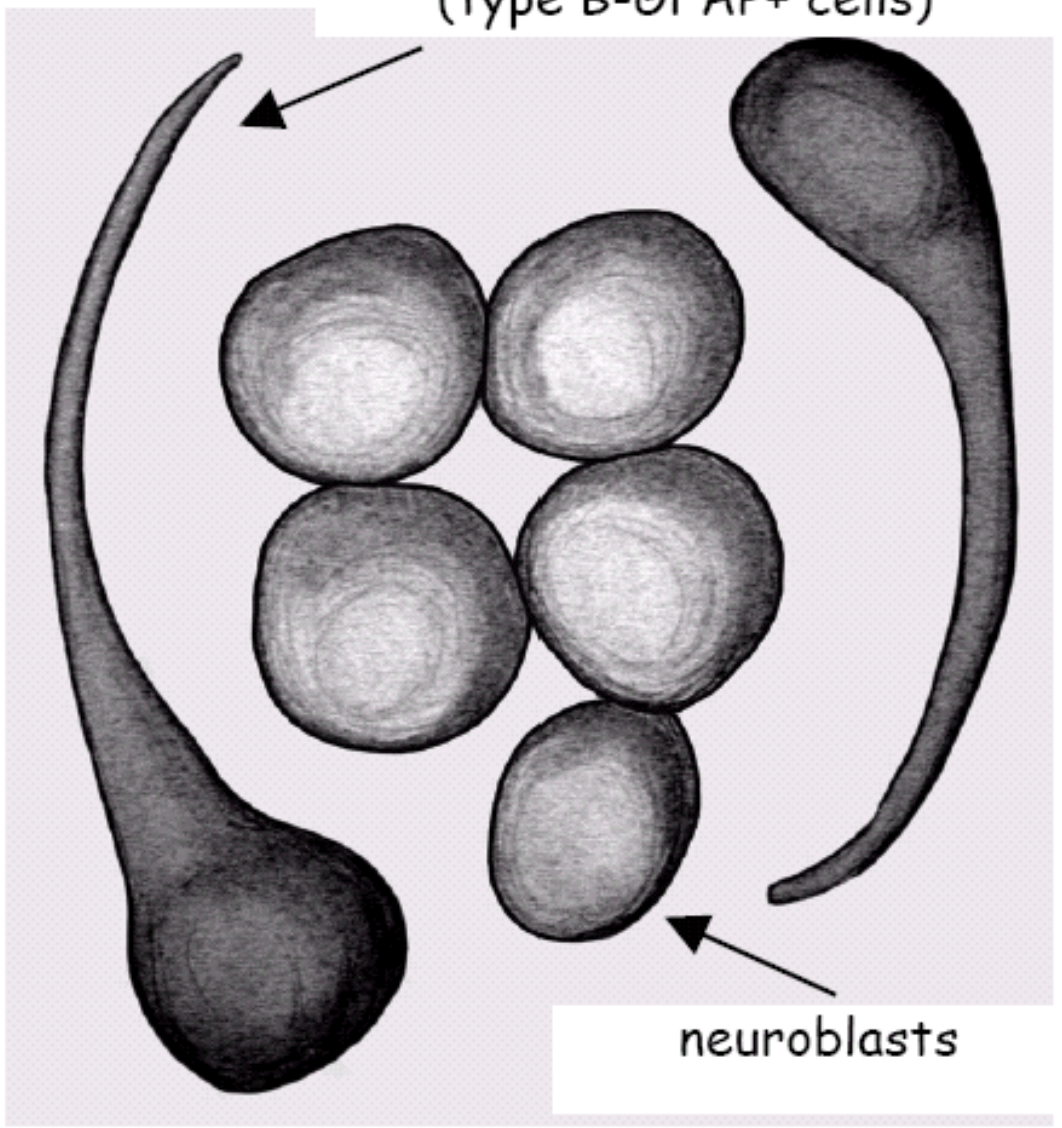

Figure 3. Specific cellular compartments in the SVZ. A.) Superimposition of the immunostainings for GAT4 (left) and GLAST (right) in a coronal section of the proximal RMS. Scale bar: $20 \mu \mathrm{m}$. B) A schematic diagram illustrating the ensheathment of neuroblasts by astrocyte-like cells.

\section{Which Cells are the Stem Cells?}

Uncovering the identity of neural stem cells has been the subject of intense research and debate for the past decade. It is now well accepted that GFAP-positive cells and not ependymal cells have stem cell attributes. ${ }^{27,32,38,41,61}$ This finding was at first surprising, however, as the stem cell nature of cells with astrocytic attributes appears univer- sal. ${ }^{5,7}$ For example, early work in adult birds reported that neural stem cells had characteristics of radial glia. ${ }^{8}$ Furthermore, in the developing rodent brain radial glia have long been known to produce cortical astrocytes, but recent data indicate that radial glia might also divide asymmetrically to produce cortical neurons. ${ }^{50,71,84,85}$ 
A

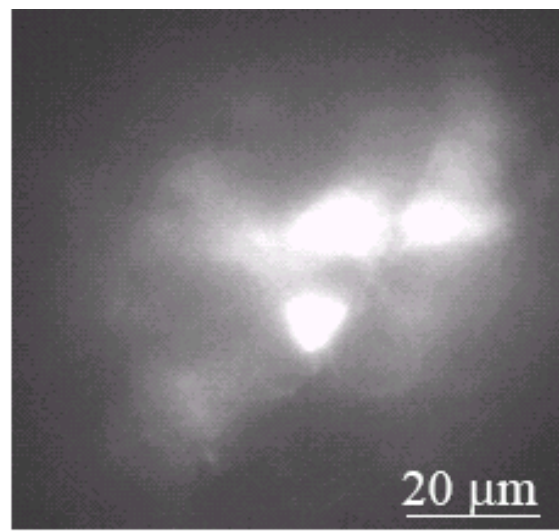

B
a. Control
b. Meclofenamic acid

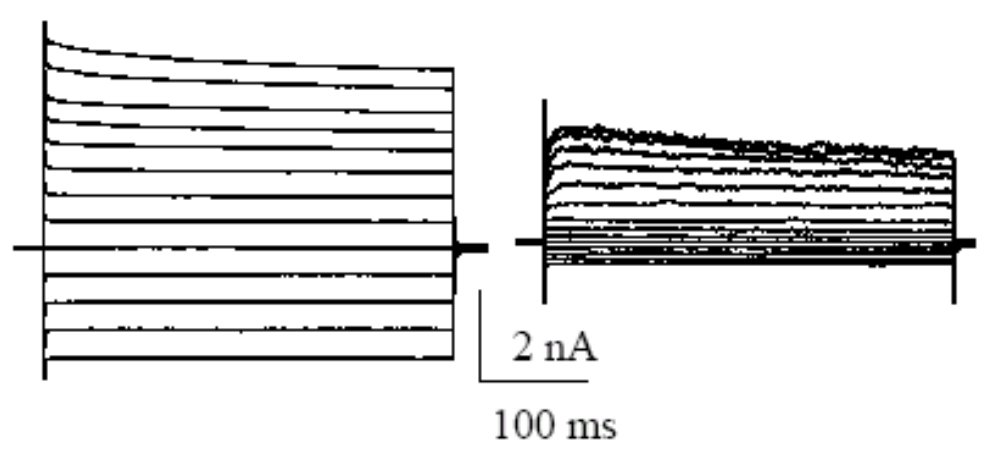

Figure 4. Astrocyte-like cells are dye-coupled. A) Photograph of lucifer yellow coupled astrocyte-like cells recorded in an acute coronal slice from a transgenic mouse expressing GFP under the GFAP promoter. B) Traces of currents in response to depolarizing voltage steps from -160 to $+80 \mathrm{mV}$ under control condition and following application of $100 \mathrm{iM}$ meclofenamic acid. The cells were held at $-70 \mathrm{mV}$.

Although GFAP-immunopositive (GFAP+) cells in the SVZ were called astrocytes, it is important to determine whether they express features in common with astrocytes beyond GFAP expression. The definition of an astrocyte has raised concern over the past few years but it is safe to assume that mature astrocytes share (but are not limited to) the following features: expression of certain GABA and glutamate transporters, presence of specialized contacts onto blood vessels, absence of axons, presence of glycogen granules, close contact with neuronal elements, and typical biophysical features characterized by the lack of action potential and expression of large resting $\mathrm{K}^{+}$ conductance. ${ }^{77,114}$ Among these properties, GFAP+ cells of the SVZ immunostain positive for the glutamate transporters GLAST, ${ }^{19,25}$ which is exclusively expressed in astrocytes. ${ }^{29,99,104}$ GFAP+ cells of the SVZ also express functional GABA transporters ${ }^{19}$ and ensheath neuronal precursors along their route to the olfactory bulb (vide supra). They display glycogen granules ${ }^{91,109}$ and close contacts with blood vessels (Figure 4) ${ }^{91}$ Their biophysical properties have, however, not been reported. Unpublished observations from Liu and Bordey suggest that GFAP+ cells in the striatal SVZ recorded in transgenic mice expressing GFP under the GFAP promoter display electrophysiological properties between those of radial glia and astrocytes. In particular, they display dye coupling to 3 or 4 surrounding GFAP+ cells (Figure 4A), have hyperpolarized resting membrane potentials (mean of $-85 \mathrm{mV}$ ), do not generate action potentials upon current injection, and express large passive currents as observed in mature astrocytes (Figure 4Ba) ${ }^{23,59}$ These passive currents are significantly reduced by gap junction channel blockers, meclofenamic acid (Figure 4Bb) or carbenoxolone, and are thus mostly due to electrical coupling (i.e. gap junction conductance) while passive currents in astrocytes are independent of electrical coupling and are presumably due to a large background $\mathrm{K}^{+}$ conductance. ${ }^{114}$ Upon blockade of gap junction coupling, GFAP+ cells of the SVZ display a small background $\mathrm{K}^{+}$ conductance and an outwardly rectifying current profile, resembling that of radial glia in acute slices from mice. ${ }^{9}$ Because radial glia give rise to GFAP+ cells in the SVZ, it is tempting to hypothesize that these GFAP+ cells remain in an intermediate state of transformation from radial glia possibly due to the persistent expression of immature environmental cues in the SVZ. ${ }^{46}$ These findings and hypothesis further challenge the definition of astrocytes and its appellation, and question whether mature astrocytes derived from radial glial cell transformation could regain neural stem cell potential if placed in an appropriate neurogenic environment.

\section{Why does Neurogenesis Persist?}

Although this question has not been definitely answered, Altman in 1967 suggested that the newly generated interneurons may be responsible for neural plasticity or may be the substrate of memory. ${ }^{3}$ In 1966, he refined his hypothesis and proposed that the plasticity or memory mediated by the interneurons formed postnatally in the cerebellum, dentate gyrus or olfactory bulb is associated with a circumscribed class of functions, namely the acquisition of locomotor memory (cerebellum) and the fixation of behavior patterns relating to affective, needcatering functions (olfactory bulb, hippocampus) and not with memory processes related to cognitive instrumental functions. ${ }^{4}$ This concept has been further extended and supported by the work of Nottebohm and colleagues in the adult avian forebrain, in particular songbirds. They suggested that birth of projection neurons in the adult avian brain was related to the acquisition of perceptual or motor memories. ${ }^{6}$ Nottebohm ${ }^{86}$ proposed a model unifying the combined role of synaptic plasticity and neuronal replacement in promoting long-term memory at least for some kinds of neurons such as projection neurons in the avian brain and olfactory bulb neurons in the rodent brain. This model still needs to be validated. 

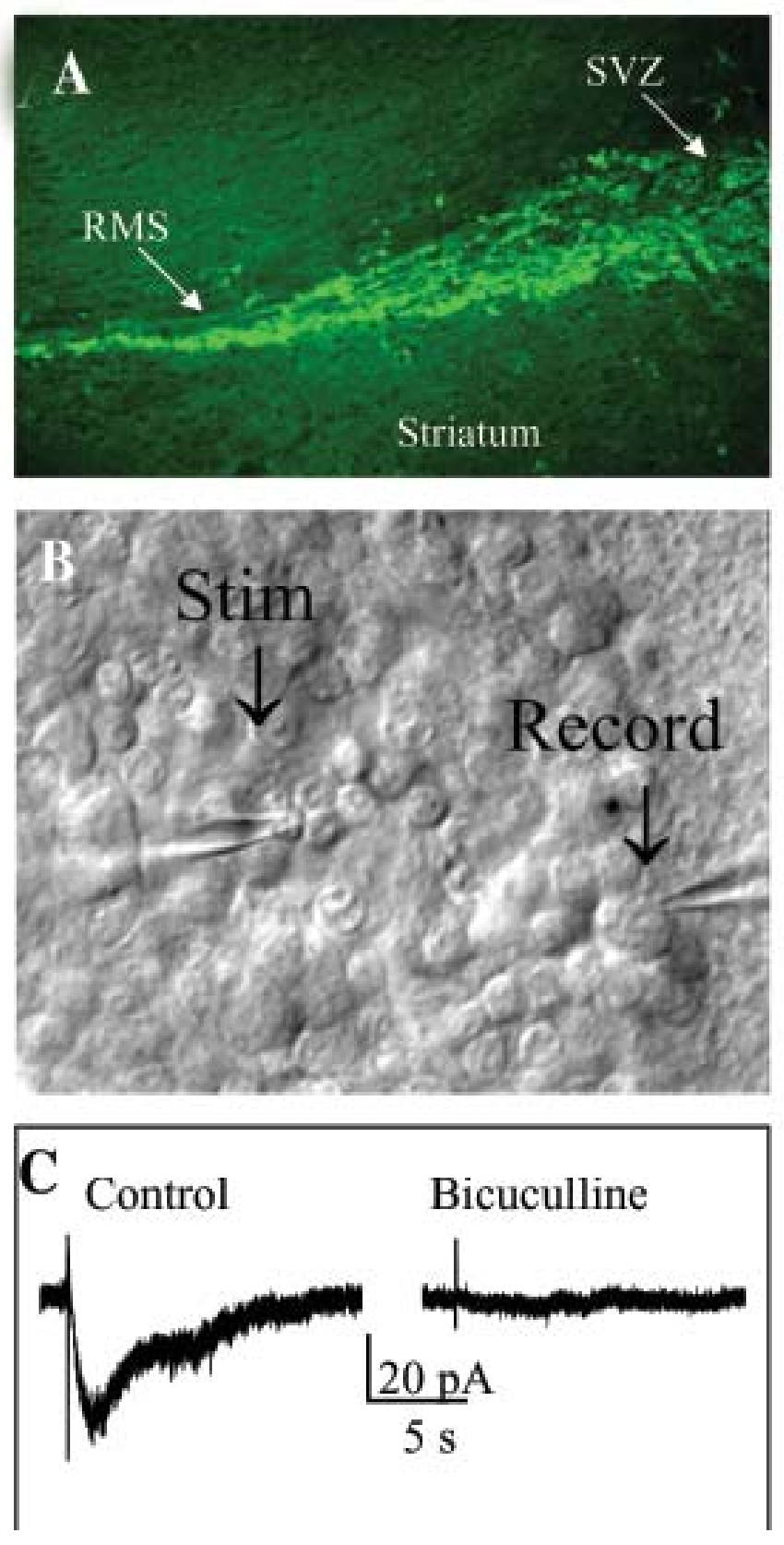

Figure 5. GABAergic signaling between SVZ precursors. A. Photograph of GABA immunostaining in a sagittal section including the anterior SVZ and proximal RMS. B) Photographs illustrating a representative position of the stimulating electrode (stim) with respect to the recorded cell (record). C) Repetitive focal electrical stimulation in the SVZ (5 pulses of $200 \mu$ s at 50 $\mathrm{Hz})$ induced inward currents in astrocyte-like cells that are blocked with bicuculline $(100 \mu \mathrm{M})$.

\section{Non-synaptic Communication in Control of Neurogenesis in the SVZ}

This paragraph argues for the view that intercellular signaling between neural stem cells and neuroblasts in the $\mathrm{SVZ}$ is critical for controlling postnatal neurogenesis (including proliferation, migration, survival/apoptosis, differentiation), and that non-synaptic communication between SVZ precursors displays characteristics of that between cells of neuron-glial networks elsewhere in the brain. Intercellular signaling can be mediated via diffusible molecules or via extracellular matrix protein and cell-cell contact. ${ }^{35}$ Extracellular matrix proteins in the SVZ are thought to maintain an immature environment that promotes neurogenesis. The SVZ is thus considered to be a special neurogenic niche while the mature brain lacks immature cues or even expresses inhibitory molecules for neurogenesis. Diffusible molecules can promote interactions between SVZ precursors, between ependymal cells and precursors, and between mature cells in the surrounding parenchyma and SVZ precursors. This paragraph will be focused on diffusible molecules with a special emphasis on the neurotransmitter GABA that provides signals between astrocyte-like cells and neuroblasts, and nitric oxide (NO) that provides communication signals between neurons and 
neuronal precursors. It is worth mentioning an important intercellular interaction between ependymal cells and astrocyte-like cells. Indeed, ependymal cells produce noggin, an antagonist of BMP signaling, which prevents glial differentiation of SVZ cells induced by BMPs, ${ }^{64}$ further emphasizing this notion of a special neurogenic niche. Several other factors including Eph/ephrin signaling, ${ }^{33}$ Sonic hedgehog, ${ }^{60}$ prolactin, ${ }^{103}$ adrenal hormones ${ }^{92}$ affect some aspect of neurogenesis in particular proliferation and are not all listed in this review. The targeted cells of these molecules remain largely unknown.

\section{GABAergic Signaling Controls Astrocyte-like Cell Proliferation}

GABA plays an important signaling role in developmental processes, such as embryonic cell proliferation, ${ }^{51,68}$ migration, ${ }^{13,14,15,16,43}$ and differentiation. . $^{10,31,72,74,75,81,88,106,107}$ The recent finding of GABA and its synthetic enzyme (glutamic acid decarboxylase 67, GAD-67) in neuroblasts ${ }^{18,81,108,115}$ (Figure 5A) but not in astrocyte-like cells $^{65}$ suggested the existence of a GABAergic signaling between SVZ cells. To consider GABA as an intercellular signaling molecule, GABA needs to be released, GABA receptors activated and GABA removed from the extracellular space since GABA is not degraded.

The action of GABA can be mediated by at least three types of GABA receptors called $\mathrm{GABA}_{\mathrm{A}}, \mathrm{GABA}_{\mathrm{B}}$ and GABA $_{C}$ receptors. ${ }^{30} \mathrm{GABA}_{\mathrm{B}}$ and $\mathrm{GABA}_{\mathrm{C}}$ receptors have not been detected in neuronal progenitors and agonists of $\mathrm{GABA}_{\mathrm{B}}$ receptors do not affect the migration or proliferation of neuroblasts. ${ }^{18,81,115}$ The expression of $\mathrm{GABA}_{\mathrm{A}}$ receptor subunit transcripts and proteins were analyzed using polymerase chain reaction (PCR) and immunocytochemistry in neuroblasts in isolated cultures ${ }^{108}$ and neurospheres. ${ }^{81}$ Furthermore, using electrophysiological techniques, $\mathrm{GABA}_{\mathrm{A}}$ receptors $\left(\mathrm{GABA}_{\mathrm{A}} \mathrm{Rs}\right)$ were identified in both neuroblasts ${ }^{115}$ and astrocyte-like cells. ${ }^{65}$ Furthermore, GABA ${ }_{A}$ Rs in SVZ cells are tonically activated by endogenous $\mathrm{GABA},{ }^{18,81}$ suggesting that there is enough ambient GABA to activate GABA $_{A}$ Rs in SVZ precursors. Using mass spectrometry and patch-clamp recordings, it was reported that SVZ precursors spontaneously release GABA. ${ }^{18,65,81}$ Liu ,et al., in 2004, also reported that non-synaptic GABA released from SVZ precursors following extracellular $\mathrm{KCl}$ application or tetanic stimulation activates $\mathrm{GABA}_{\mathrm{A}} \mathrm{Rs}$ in astrocyte-like cells (Figure 5B). ${ }^{65}$ Regarding GABA uptake, pharmacological inhibition of GABA transporters in particular GAT4 ${ }^{22}$ altered

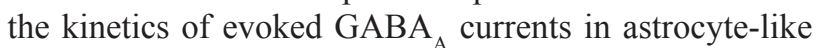
cells $^{65}$ and reduced the speed of neuroblast migration via GABA $\mathrm{R}$ activation. ${ }^{18}$ In addition, strong GAT4 immunostaining was observed in astrocyte-like cells but not in neuroblasts (Figure 3A). ${ }^{18}$ Therefore, in the SVZ GABA transporters play an important role in clearing GABA released from neuroblasts thereby controlling the degree of $\mathrm{GABA}_{\mathrm{A}} \mathrm{R}$ activation in astrocyte-like cells. The SVZ can thus be viewed as a local GABAergic network where GABA provides communication signals between precursors despite the absence of conventional synapses. While the role of synaptically released GABA on the biology of astrocytes remains unclear, tonic $\mathrm{GABA}_{\mathrm{A}} \mathrm{R}$ activation in astrocyte-like cells and neuroblasts was found to reduce their proliferation. ${ }^{65,81}$

Summary and model of GABAergic signaling between SVZ cells: As more neuroblasts are generated, it is expected that more GABA is released in the extracellular space resulting in increased ambient GABA levels and $G_{A B A} R$ activation in SVZ precursors. Since astrocyte-like cells generate neuroblasts, ${ }^{38,40 \mathrm{a}}$ an increase in the number of neuroblasts seems to serve as a negative feedback to decrease astrocyte-like cell proliferation and neuroblast production by activating $\mathrm{GABA}_{\mathrm{A}}$ Rs. This negative feedback fits well with the constant migration of neuroblasts away from the SVZ to the olfactory bulb, ${ }^{28,66,70}$ which limits ambient GABA accumulation, and with the increased proliferation of astrocyte-like cells following elimination of neuroblasts. ${ }^{40}$ A similar feedback exerted on precursor proliferation by GABA may also occur in the embryonic ventricular zone where tonic $\mathrm{GABA}_{\mathrm{A}} \mathrm{R}$ activation by ambient GABA limits the proliferation of precursors. ${ }^{51,68}$ Interestingly, the proliferative precursors in the ventricular zone, which are thought to be radial glial cells, ${ }^{84,85}$ transform into astrocytelike cells in the postnatal SVZ. ${ }^{76,111}$ The postnatal SVZ can thus be viewed as an interface between the embryonic ventricular zone and the adult brain, sharing properties of both systems.

It is interesting to draw parallels between the neuroblast and astrocyte-like cell communication, and that between neurons and astrocytes. At GABAergic synapses, synaptically released GABA diffuses outside the synaptic cleft and activates GABA transporters in astrocytes. ${ }^{56}$ Furthermore, inhibition of GABA transporters affects the degree of postsynaptic $\mathrm{GABA}_{\mathrm{A}}$ receptor activation and thus synaptic transmission. ${ }^{34,48,96,98,113}$ Astrocytic processes encapsulate either one synapse or a group of GABAergic synapses like the cerebellar glomeruli. ${ }^{89}$ This latter configuration resembles that of the SVZ where processes of astrocyte-like cells encapsulate clusters of migrating neuroblasts (Figure 3).

\section{Influence from Surrounding Mature Nervous Tissue}

Thus far, we described the SVZ as an independent network from surrounding brain regions. However, SVZ cells are adjacent to the striatum, which is rich in GABAergic cells and terminals. Furthermore, although glial processes ensheath migrating neuroblasts, migrating neuroblasts can be in contact with the surrounding neuropil (Figure 5B). ${ }^{91}$ However, it remains unknown whether synaptically released GABA from GABAergic striatal terminals could diffuse from the striatum to the SVZ and activate $\mathrm{GABA}_{\mathrm{A}}$ receptors in neuroblasts and/or astrocyte-like cells. However, here are two examples to illustrate that mature cells adjacent to the SVZ can influence neurogenesis. The diffusible factor Slit, which is secreted from the septum, is a chemorepellent that directs the migration of SVZ neuroblasts toward the olfactory bulb. ${ }^{52,53,83}$ Moreno-Lopez, et al., recently reported that in the adult mouse brain, the SVZ is surrounded by differentiated neurons expressing neuronal nitric oxide 
synthase (nNOS). ${ }^{78}$ These neurons project rich axonal networks in which SVZ neuroblasts are immersed. The spatial proximity between precursor cells and potential NO sources raised the question of whether $\mathrm{NO}$ may be one of the factors controlling neurogenesis in the adult brain. Systemic administration of NOS inhibitors to adult mice produced an increase in the number of mitotic cells in the SVZ, RMS, and olfactory bulb without affecting apoptosis. ${ }^{78}$ In the SVZ, this effect was exerted selectively on a precursor subpopulation expressing nestin, presumably the type $\mathrm{C}$ cells but not on the neuroblasts or astrocyte-like cells. In addition, in the olfactory bulb, chronic NOS inhibition caused a delay in neuronal differentiation. Postmitotic cell survival and migration were not affected when NO production was impaired. All together these data suggested that NO, produced by nitrergic neurons in the adult SVZ and olfactory bulb, exerts a negative control on the size of the undifferentiated precursor pool and promotes neuronal differentiation.

\section{How to Promote Neurogenesis in the Adult Brain}

\section{Does the SVZ Exist in Humans?}

Neural progenitors have been isolated from regions along the lateral ventricular wall of humans with intractable temporal lobe epilepsy. ${ }^{47,57,93,94}$ More recently Sanai,et al., described the presence of GFAP-positive cells lining the lateral ventricles of humans with stem cell attributes (i.e. they proliferate in vivo and behave as multipotent progenitor cells in vitro). ${ }^{101}$ However, the organization of the human SVZ differs from that of rodent or monkey in that it is essentially formed by a ribbon of GFAP+ cells with no or very few neuroblasts. Furthermore, Sanai, et al., ${ }^{101}$ did not observe chains of migrating neuroblasts in the SVZ or in the pathway to the olfactory bulb. However, newly generated neurons have been observed in the human olfactory bulb suggesting that either neuroblasts migrate from the SVZ to the olfactory bulb or persistent progenitors populate the olfactory bulb. ${ }^{12}$ All of these studies were performed on tissue from adult humans. It remains to be determined whether the SVZ in infants or young adults is different from that in adults since neurogenesis decreases during aging. ${ }^{42}$

\section{Challenges for Studying and Promoting Neurogenesis}

Recruitment of new neurons is affected by environmental variables. It is known that captivity, ${ }^{11}$ environmental simplicity as opposed to an enriched environment, ${ }^{55}$ and physical inactivity, ${ }^{112}$ significantly reduce neurogenesis in the adult brain. This has been essentially studied in birds and in the dentate gyrus of mammals but is likely to be true in the SVZ of mammals. It is thus critical to study neurogenesis and its regulation in animals as previously performed in their normal environment as performed. ${ }^{11,21}$

It is critical to define appropriate methods to deliver drugs and to identify the appropriate drugs to be delivered. ${ }^{49,92}$ Our present knowledge suggests two possible strategies for promoting repair using neural stem cells. One approach is a cell replacement strategy to achieve structural brain repair, where neural stem cells are isolated from CNS tissue, expanded in vitro and grafted into the brain. The second, more elegant but more difficult approach is to recruit endogenous neural stem cells from the SVZ to proliferate, migrate, differentiate into functional glia or neurons, and properly integrate and survive to achieve self-repair. Both the grafting and recruitment approaches will require a thorough understanding of the factors and signals regulating neurogenesis. Furthermore, therapeutic progress will depend on the ability to deliver the appropriate factors or to regulate their endogenous expression, which requires close work with bioengineering research laboratories.

\section{Aknowledgments}

This work was supported by a grant from the National Institute of Health R21NS044161-01 and National Multiple Sclerosis Society Research Award.

\section{References}

1. Allen E: Cessation of mitosis in central nervous system of the albino rat. J Comp Neurol 22: 547568,1912

2. Altman J: Autoradiographic investigation of cell proliferation in the brains of rats and cats. Anat Rec 145:573-591, 1963

3. Altman J: Postnatal growth and differentiation of the mammalian brain, with implications for a morphological theory of memory, in Quarton GCeal (ed): The Neurosciences. New York: Rockefeller University Press, 1967, pp 723-743

4. Altman J: Autoradiographic and histological studies of postnatal neurogenesis. IV. Cell proliferation and migration in the anterior forebrain, with special reference to persisting neurogenesis in the olfactory bulb. J Comp Neurol 137:433-457, 1969

5. Alvarez-Buylla A, Garcia-Verdugo JM, Tramontin AD: A unified hypothesis on the lineage of neural stem cells. Nat Rev Neurosci 2:287-293, 2001

6. Alvarez-Buylla A, Kirn JR, Nottebohm F: Birth of projection neurons in adult avian brain may be related to perceptual or motor learning. Science 249:1444-1446, 1990

7. Alvarez-Buylla A, Seri B, Doetsch F: Identification of neural stem cells in the adult vertebrate brain. Brain Res Bull 57:751-758, 2002

8. Alvarez-Buylla A, Theelen M, Nottebohm F: Proliferation "hot spots" in adult avian ventricular zone reveal radial cell division. Neuron 5:101-109, 1990

9. Bahrey HL, Moody WJ (2003) Voltage-gated currents, dye and electrical coupling in the embryonic mouse neocortex. Cereb Cortex 13:239-251, 2003

10. Barker JL, Behar T, Li YX, et al: GABAergic cells 
and signals in CNS development. Perspect Dev Neurobiol 5:305-322, 1998

11. Barnea A, Nottebohm F: Seasonal recruitment of hippocampal neurons in adult free-ranging blackcapped chickadees. Proc Natl Acad Sci U S A 91:11217-11221, 1994

12. Bedard A, Parent A: Evidence of newly generated neurons in the human olfactory bulb. Brain Res Dev Brain Res 151:159-168, 2004

13. Behar TN, Li YX, Tran HT, et al: GABA stimulates chemotaxis and chemokinesis of embryonic cortical neurons via calcium-dependent mechanisms. J Neurosci 16:1808-1818, 1996

14. Behar TN, Schaffner AE, Scott CA, et al: GABA receptor antagonists modulate postmitotic cell migration in slice cultures of embryonic rat cortex. Cereb Cortex 10:899-909, 2000

15. Behar TN, Schaffner AE, Scott CA, et al: Differential response of cortical plate and ventricular zone cells to GABA as a migration stimulus. J Neurosci 18:6378-6387, 1998

16. Behar TN, Schaffner AE, Tran HT, et al: GABAinduced motility of spinal neuroblasts develops along a ventrodorsal gradient and can be mimicked by agonists of GABAA and GABAB receptors. J Neurosci Res 42:97-108, 1995

17. Blakemore WF: The ultrastructure of the subependymal plate in the rat. J Anat 104:423433, 1969

18. Bolteus A, Bordey A: Local GABA signaling regulates neuronal precursor migration in the postnatal subventricular zone. Soc Neurosci, 2004 (Abstract)

19. Bolteus AJ, Bordey A: GABA release and uptake regulate neuronal precursor migration in the Postnatal Subventricular Zone. J Neurosci 24:7623-7631, 2004

20. Bonfanti L, Theodosis DT: Expression of polysialylated neural cell adhesion molecule by proliferating cells in the subependymal layer of the adult rat, in its rostral extension and in the olfactory bulb. Neuroscience 62:291-305, 1994

21. Boonstra R, Galea L, Matthews S,et al: Adult neurogenesis in natural populations. Can $\mathbf{J}$ Physiol Pharmacol 79:297-302, 2001

22. Borden LA: GABA transporter heterogeneity: pharmacology and cellular localization. Neurochem Int 29:335-356, 1996

23. Bordey A, Sontheimer H: Ion channel expression by astrocytes in situ: comparison of different CNS regions. Glia 30:27-38, 2000

24. Boulder Committee: Embryonic vertebrate central nervous system: revised terminology. Anat Rec 166:257-261, 1970

25. Braun N, Sevigny J, Mishra SK, et al: Expression of the ecto-ATPase NTPDase 2 in the germinal zones of the developing and adult rat brain. Eur J
Neurosci 17:1355-1364, 2003

26. Bryans WA: Mitotic activity in the brain of the adult rat. Anatomical Record 133:65-73, 1959

27. Capela A, Temple S: LeX/ssea-1 is expressed by adult mouse CNS stem cells, identifying them as nonependymal. Neuron 35:865-875, 2002

28. Carleton A, Petreanu LT, Lansford R, et al: Becoming a new neuron in the adult olfactory bulb. Nat Neurosci 6:507-518, 2003

29. Chaudhry FA, Lehre KP, van Lookeren Campagne $\mathrm{M}$, et al: Glutamate transporters in glial plasma membranes: highly differentiated localizations revealed by quantitative ultrastructural immunocytochemistry. Neuron 15:711-720, 1995

30. Chebib M, Johnston GA: The 'ABC' of GABA receptors: a brief review. Clin Exp Pharmacol Physiol 26:937-940, 1999

31. Cherubini E, Gaiarsa JL, Ben Ari Y: GABA: an excitatory transmitter in early postnatal life. Trends Neurosci 14:515-519, 1991

32. Chiasson BJ, Tropepe V, Morshead CM, et al: Adult mammalian forebrain ependymal and subependymal cells demonstrate proliferative potential, but only subependymal cells have neural stem cell characteristics. J Neurosci 19:4462-4471, 1999

33. Conover JC, Doetsch F, Garcia-Verdugo JM, et al: Disruption of Eph/ephrin signaling affects migration and proliferation in the adult subventricular zone. Nat Neurosci 3:1091-1097, 2000

34. Dingledine R, Korn SJ: Gamma-aminobutyric acid uptake and the termination of inhibitory synaptic potentials in the rat hippocampal slice. J Physiol (Lond) 366:387-409, 1985

35. Doetsch F: A niche for adult neural stem cells. Curr Opin Genet Dev 13:543-550, 2003

36. Doetsch F: The glial identity of neural stem cells. Nat Neurosci 6:1127-1134, 2003

37. Doetsch F, Alvarez-Buylla A: Network of tangential pathways for neuronal migration in adult mammalian brain. Proc Natl Acad Sci U SA 93:14895-14900, 1996

38. Doetsch F, Caille I, Lim DA, et al: Subventricular zone astrocytes are neural stem cells in the adult mammalian brain. Cell 97:703-716, 1999

39. Doetsch F, Garcia-Verdugo JM, Alvarez-Buylla A: Cellular composition and three-dimensional organization of the subventricular germinal zone in the adult mammalian brain. J Neurosci 17:50465061, 1997

40. Doetsch F, Garcia-Verdugo JM, Alvarez-Buylla A: Regeneration of a germinal layer in the adult mammalian brain. Proc Natl Acad Sci U S A 96:11619-11624, 1999

41. Doetsch F, Petreanu L, Caille I, et al: EGF converts transit-amplifying neurogenic precursors in the 
adult brain into multipotent stem cells. Neuron 36:1021-1034, 2002

42. Enwere E, Shingo T, Gregg C, et al: Aging results in reduced epidermal growth factor receptor signaling, diminished olfactory neurogenesis, and deficits in fine olfactory discrimination. J Neurosci 24:8354-8365, 2004

43. Fueshko SM, Key S, Wray S: GABA inhibits migration of luteinizing hormone-releasing hormone neurons in embryonic olfactory explants. J Neurosci 18:2560-2569, 1998

44. Garcia AD, Doan NB, Imura T, et al: GFAPexpressing progenitors are the principal source of constitutive neurogenesis in adult mouse forebrain. Nat Neurosci 7: 1233-1241, 2004

45. Garcia-Verdugo JM, Doetsch F, Wichterle H, et al: Architecture and cell types of the adult subventricular zone: in search of the stem cells. $\mathbf{J}$ Neurobiol 36:234-248, 1998

46. Gates MA, Thomas LB, Howard EM, et al: Cell and molecular analysis of the developing and adult mouse subventricular zone of the cerebral hemispheres. J Comp Neurol 361:249-266, 1995

47. Goldman SA: Adult neurogenesis: from canaries to the clinic. J Neurobiol 36:267-286, 1998

48. Hablitz JJ, Lebeda FJ: Role of uptake in gammaaminobutyric acid (GABA)-mediated responses in guinea pig hippocampal neurons. Cell Mol Neurobiol 5:353-371, 1985

49. Hallbergson AF, Gnatenco C, Peterson DA: Neurogenesis and brain injury: managing a renewable resource for repair. J Clin Invest 112:1128-1133, 2003

50. Hartfuss E, Galli R, Heins N, Gotz M: Characterization of CNS precursor subtypes and radial glia. Dev Biol 229: 15-30, 2001

51. HaydarTF, Wang F, Schwartz ML, et al: Differential modulation of proliferation in the neocortical ventricular and subventricular zones. J Neurosci 20:5764-5774, 2000

52. $\mathrm{Hu} \mathrm{H}$ : Chemorepulsion of neuronal migration by Slit2 in the developing mammalian forebrain. Neuron 23:703-711, 1999

53. $\mathrm{Hu} \mathrm{H}$, Rutishauser U: A septum-derived chemorepulsive factor for migrating olfactory interneuron precursors. Neuron 16:933-940, 1996

54. Jankovski A, Sotelo C: Subventricular zoneolfactory bulb migratory pathway in the adult mouse: cellular composition and specificity as determined by heterochronic and heterotopic transplantation. J Comp Neurol 371:376-396, 1996

55. Kempermann G, Kuhn HG, Gage FH: More hippocampal neurons in adult mice living in an enriched environment. Nature 386:493-495, 1997

56. Kinney GA, Spain WJ: Synaptically evoked GABA transporter currents in neocortical glia. J Neurophysiol 88:2899-2908, 2002
57. Kirschenbaum B, Nedergaard M, Preuss A, et al: In vitro neuronal production and differentiation by precursor cells derived from the adult human forebrain. Cereb Cortex 4:576-589, 1994

58. Kishi K: Golgi studies on the development of granule cells of the rat olfactory bulb with reference to migration in the subependymal layer. J Comp Neurol 258: 112-124, 1987

59. Kressin K, Kuprijanova E, Jabs R, et al: Developmental regulation of $\mathrm{Na}^{+}$and $\mathrm{K}^{+}$ conductances in glial cells of mouse hippocampal brain slices. Glia 15:173-187, 1995

60. Lai K, Kaspar BK, Gage FH, et al: Sonic hedgehog regulates adult neural progenitor proliferation in vitro and in vivo. Nat Neurosci 6:21-27, 2003

61. Laywell ED, Rakic P, Kukekov VG, et al: Identification of a multipotent astrocytic stem cell in the immature and adult mouse brain. Proc Natl Acad Sci U S A 97:13883-13888, 2000

62. Levison SW, Goldman JE: Both oligodendrocytes and astrocytes develop from progenitors in the subventricular zone of postnatal rat forebrain. Neuron 10:201-212, 1993

63. Levison SW, Goldman JE: Multipotential and lineage restricted precursors coexist in the mammalian perinatal subventricular zone. J Neurosci Res 48:83-94, 1997

64. Lim DA, Tramontin AD, Trevejo JM: Noggin antagonizes BMP signaling to create a niche for adult neurogenesis. Neuron 28:713-726, 2000

65. Liu X, Qin W, Bordey A: Nonsynaptic GABAergic signaling between neuronal precursors and astrocyte-like cells of the postnatal subventricular zone. Soc Neurosci, 2004 (Abstract)

66. Lois C,Alvarez-Buylla A: Long-distance neuronal migration in the adult mammalian brain. Science 264:1145-1148, 1994

67. Lois C, Garcia-Verdugo JM, Alvarez-Buylla A: Chain migration of neuronal precursors. Science 271:978-981, 1996

68. LoTurco JJ, Owens DF, Heath MJ, et al: GABA and glutamate depolarize cortical progenitor cells and inhibit DNA synthesis. Neuron 15:1287-1298, 1995

69. Luskin MB: Restricted proliferation and migration of postnatally generated neurons derived from the forebrain subventricular zone. Neuron 11:173189, 1993

70. Luskin MB, Boone MS: Rate and pattern of migration of lineally-related olfactory bulb interneurons generated postnatally in the subventricular zone of the rat. Chem Senses 19:695-714, 1994

71. Malatesta P, Hartfuss E, Gotz M: Isolation of radial glial cells by fluorescent-activated cell sorting reveals a neuronal lineage. Development 127:5253-5263, 2000 
72. Maric D, Liu QY, Maric I, et al:GABA expression dominates neuronal lineage progression in the embryonic rat neocortex and facilitates neurite outgrowth via GABA(A) autoreceptor/Clchannels. J Neurosci 21:2343-2360, 2001

73. Marshall CA, Suzuki SO, Goldman JE: Gliogenic and neurogenic progenitors of the subventricular zone: who are they, where did they come from, and where are they going? Glia 43:52-61, 2003

74. Marty S, Berninger B, Carroll P, et al: GABAergic stimulation regulates the phenotype of hippocampal interneurons through the regulation of brain-derived neurotrophic factor. Neuron 16:565-570, 1996

75. Meier E, Hertz L, Schousboe A: Neurotransmitters as developmental signals. Neurochem Int 19:115,1991

76. Merkle FT, Tramontin AD, Garcia-Verdugo JM, et al: Radial glia give rise to adult neural stem cells in the subventricular zone. Proc Natl Acad Sci U S A 101:17528-17532, 2004

77. Montgomery DL: Astrocytes : forms, functions, and roles in disease. Vet Pathol 31:145-167, 1994

78. Moreno-Lopez B, Noval JA, Gonzalez-Bonet LG, et al: Morphological bases for a role of nitric oxide in adult neurogenesis. Brain Res 869:244-250, 2000

79. Moreno-Lopez B, Romero-Grimaldi C, Noval JA, et al: Nitric oxide is a physiological inhibitor of neurogenesis in the adult mouse subventricular zone and olfactory bulb. J Neurosci 24:85-95, 2004

80. Morshead CM, Reynolds BA, Craig CG, et al: Neural stem cells in the adult mammalian forebrain: a relatively quiescent subpopulation of subependymal cells. Neuron 13:1071-1082, 1994

81. Nguyen L, Malgrange B, Breuskin I, et al: Autocrine/paracrine activation of the GABA(A) receptor inhibits the proliferation of neurogenic polysialylated neural cell adhesion molecule-positive (PSA-NCAM+) precursor cells from postnatal striatum. J Neurosci 23:3278-3294, 2003

82. Nguyen L, Rigo JM, Rocher V, et al: Neurotransmitters as early signals for central nervous system development. Cell Tissue Res 305:187-202, 2001

83. Nguyen-Ba-Charvet KT, Picard-Riera N, TessierLavigne M, et al: Multiple roles for slits in the control of cell migration in the rostral migratory stream. J Neurosci 24:1497-1506, 2004

84. Noctor SC, Flint AC, Weissman TA, et al: Neurons derived from radial glial cells establish radial units in neocortex. Nature 409:714-720, 2001

85. Noctor SC, Flint AC, Weissman TA, et al: Dividing precursor cells of the embryonic cortical ventricular zone have morphological and molecular characteristics of radial glia. J Neurosci 22:3161-3173, 2002

86. Nottebohm F: Neuronal replacement in adulthood. Ann N Y Acad Sci 457:143-161, 1985

87. Nottebohm F: Why are some neurons replaced in adult brain? J Neurosci 22:624-628, 2002
88. Owens DF, Kriegstein AR: Is there more to GABA than synaptic inhibition? Nat Rev Neurosci 3:715727, 2002

89. Palay SL, Chan-Palay V: Cerebellar Cortex, cytology and Organization. New York: Springer-Verlag, 1974, pp 236

90. Peretto P, Merighi A, Fasolo A, Bonfanti L: Glial tubes in the rostral migratory stream of the adult rat. Brain Res Bull 42:9-21, 1997

91. Peretto P, Merighi A, Fasolo A, et al: The subependymal layer in rodents: a site of structural plasticity and cell migration in the adult mammalian brain. Brain Res Bull 49:221-243, 1999

92. Peterson DA: Stem cells in brain plasticity and repair. Curr Opin Pharmacol 2:34-42, 2002

93. Pincus DW, Harrison-Restelli C, Barry J, et al: In vitro neurogenesis by adult human epileptic temporal neocortex. Clin Neurosurg 44:17-25, 1997

94. Pincus DW, Keyoung HM, Harrison-Restelli C, et al: Fibroblast growth factor-2/brain-derived neurotrophic factor-associated maturation of new neurons generated from adult human subependymal cells. Ann Neurol 43:576-585, 1998

95. Privat A, Leblond CP: The subependymal layer and neighboring region in the brain of the young rat. $\mathbf{J}$ Comp Neurol 146:277-302, 1972

96. Rekling JC, Jahnsen H, Mosfeldt Laursen A: The effect of two lipophilic gamma-aminobutyric acid uptake blockers in CA1 of the rat hippocampal slice. Br J Pharmacol 99:103-106, 1990

97. Reynolds BA, Weiss S: Generation of neurons and astrocytes from isolated cells of the adult mammalian central nervous system. Science 255:17071710,1992

98. Roepstorff A, Lambert JD: Factors contributing to the decay of the stimulus-evoked IPSC in rat hippocampal CA1 neurons. J Neurophysiol 72:29112926, 1994

99. Rothstein JD, Martin L, Levey AI, et al: Localization of neuronal and glial glutamate transporters. Neuron 13:713-725, 1994

100. Rousselot P, Lois C, Alvarez-Buylla A: Embryonic (PSA) N-CAM reveals chains of migrating neuroblasts between the lateral ventricle and the olfactory bulb of adult mice. J Comp Neurol 351:51-61, 1995

101. Sanai N, Tramontin AD, Quinones-Hinojosa A, et al: Unique astrocyte ribbon in adult human brain contains neural stem cells but lacks chain migration. Nature 427:740-744, 2004

102. Schmitt A, Asan E, Puschel B, et al: Cellular and regional distribution of the glutamate transporter GLAST in the CNS of rats: nonradioactive in situ hybridization and comparative immunocytochemistry. J Neurosci 17:1-10, 1997

103. Shingo T, Gregg C, Enwere E, et al: Pregnancystimulated neurogenesis in the adult female forebrain mediated by prolactin. Science 299:117-120, 2003

104. Silakova JM, Hewett JA, Hewett SJ: Naproxen re- 
duces excitotoxic neurodegeneration in vivo with an extended therapeutic window. J Pharmacol Exp Ther 309: 1060-1066, 2004

105. Smart I : The subependymal layer of the mouse brain and its cellular production as shown by radioautography after thymidine-H3 injection. J Comp Neurol 116:325-349, 1961

106. Spoerri PE: Neurotrophic effects of GABA in cultures of embryonic chick brain and retina. Synapse 2:11-22, 1988

107. Spoerri PE, Wolff JR: Effect of GABA-administration on murine neuroblastoma cells in culture. I. Increased membrane dynamics and formation of specialized contacts. Cell Tissue Res 218:567-579, 1981

108. Stewart RR, Hoge GJ, Zigova T, et al: Neural progenitor cells of the neonatal rat anterior subventricular zone express functional $\mathrm{GABA}(\mathrm{A})$ receptors. J Neurobiol 50:305-322, 2002

109. Sturrock RR, Smart IH: A morphological study of the mouse subependymal layer from embryonic life to old age. J Anat 130:391-415, 1980

110. Sundholm-Peters NL, Yang HK, Goings GE, et al: Radial glia-like cells at the base of the lateral ventricles in adult mice. J Neurocytol 33: 153-164, 2004
111. Tramontin AD, Garcia-Verdugo JM, Lim DA, et al: Postnatal development of radial glia and the ventricular zone (VZ): a continuum of the neural stem cell compartment. Cereb Cortex 13:580-587, 2003

112. van Praag H, Kempermann G, Gage FH: Running increases cell proliferation and neurogenesis in the adult mouse dentate gyrus. Nat Neurosci 2:266270, 1999

113. Wall MJ, Usowicz MM: Development of action potential-dependent and independent spontaneous GABAA receptor-mediated currents in granule cells of postnatal rat cerebellum. Eur J Neurosci 9:533-548, 1997

114. Wallraff A, Odermatt B, Willecke K, et al: Distinct types of astroglial cells in the hippocampus differ in gap junction coupling. Glia 48:36-43, 2004

115. Wang DD, Krueger DD, Bordey A: GABA depolarizes neuronal progenitors of the postnatal subventricular zone via GABA A receptor activation. J Physiol (Lond) 550:785-800, 2003

116. Yang HK, Sundholm-Peters NL, Goings GE, et al: Distribution of doublecortin expressing cells near the lateral ventricles in the adult mouse brain. $\mathbf{J}$ Neurosci Res 76:282-295, 2004 